\title{
ESTUDO SOBRE O CRESCIMENTO DE FEDEGOSO ${ }^{1}$
}

\author{
EDUARDO A. L. ERASMO 2 , SILVANO BIANCO ${ }^{3}$ e ROBINSON A. PITELLI4
}

\section{RESUMO}

O crescimento de Senna obtusifolia foi estudado sob condições de casa-de-vegetação, num delineamento inteiramente casualizado com 4 repetições. As plantas cresceram em vasos de 6 litros preenchidos com areia e irrigados com solução completa de Hoagland, duas vezes por dia. O crescimento das plantas foi avaliado a partir de 21 até 161 dias após a emergência, em intervalos de 14 dias. Os resultados evidenciaram que as plantas de $S$. obtusifolia acumularam o máximo de matéria seca aos 147 dias após à emergência (D.A.E.) com um período de maior intensidade de crescimento compreendido entre 21 e 63 D.A.E. A partir da emergência até 63 dias, o maior acúmulo de matéria seca foi verificado nas raízes, após esta data até o final do ciclo do fedegoso, maior proporção foi alocada nos caules. Aos 63 D.A.E. todas as plantas tinham florescido. A taxa de crescimento relativo decresceu rapidamente até 63 dias, mantendo-se baixa e constante até o final do período experimental. Este parâmetro de crescimento foi fortemente influenciado pela TAL, a qual foi constante após 91 dias, provavelmente devido ao auto-sombre amento da planta. A área foliar cresceu amplamente até os 35 dias, tornan do-se estável a partir dos 119 dias após a emergência das plantas. Considerando-se um período corres pondente a dois terços do ciclo médio de culturas anuais, de dez semanas, $S$. obtusifolia quando comparada a outras espécies daninhas, apresenta taxas de crescimento inicial menores, o que pode caracterizá-la como uma planta infestante tardia.

Palavras chave: Análise de crescimento, planta daninha, Senna obtusifolia, fenologia.

\section{ABSTRACT}

\section{Growth analysis of sicklepod}

The growth of Senna obtusifolia was studied under greenhouse conditions. The plants grew in 61 pots, filled with sand and irrigated with complete Hoagland's solution twice a day. The growth of the plant was evaluated from 21 to 161 days after the emergence (D.A.E.), at 14 days intervals. Results evidenced that plants of Senna obtusifolia accumulated the maximum amount of dry matter at 147 D.A.E. The greast intensity of growth occurred from 21 to 63 D.A.E. evaluation. From 63 D.A.E. all the plants had flowered . From the emergence to 63 days, the highe st amount of dry matter was partitioned in the roots. Form this evaluation to the end of the cicle of sicklepod, the majority of the dry matter was partitioned to stems. The relative growth decreased quickly until 63

1Recebido para publicação em 13/01/97 e na forma revisada em 20/09/97.

2 Professor Adjunto I da Universidade do Tocantins,UNITINS, Centro Universitário de Gurupi, Av. Qd 06, Lt 08 e 09, Jardim Sevilha, CEP 77.410-470, Gurupi-TO.

3 Professor Adjunto da FCAV-UNESP, Rodovia Carlos Tonani Km 5, CEP 14.870-000, Jaboticabal, SP.

4 Professor Titular da FCAV-UNESP, Rodovia Carlos Tonani Km 5, CEP 14.870-000, Jaboticabal, SP. 
days, maintaining a low and constant rate until the end of experimental period. This growth parameter was strongly influenced by the net assimilation rate, which was steady after 91 days, probably to due the plant selfshading. The leaf area grew vastly until 35 days and beca me steady 119 days after the plant

\section{INTRODUÇÃO}

Nos rumos do desenvolvi mento da agricultura, as plantas daninhas sempre foram consideradas organismos indesejáveis, como consequiência, as pesquisas em sua maioria foram dirigidas para análise dos efeitos negativos destas sobre as plantas cultivadas, e às práticas de seu controle.

Não entanto, o estudo da ciência deste tipo de plantas, envolve várias áreas fu nd amentais, como fi siologia, ge nética e ecologia, que subsidiam à compreen são dos padrões ecológicos e evolucionários que regem estas comunidades. Assim, Roush et al. (1990), sug ere que o desenvolvimento no controle de plantas daninhas, requer análise integrada destas ár eas, as quais influe nciam a di nâmica de populações destes tipos de plantas. Uma vez que, a es tratégia evolutiva destas espécies, lhe conferem como habitat os solos agrícolas, tornamse necessários estudos que ampliem o conhecimento dos padrões de crescimento e a

influência destes padrões na habilidade competitiva com as culturas (Gustavsson, 1989), destacando-se dentre estes, a análise quantitativa do crescimento vegetal.

Assim sendo, os estudos relativos ao crescimento e desenvolvimento das plantas, permitem a obtenção de importantes informações sobre as fases fenológicas e padrões de crescimento fornecendo subsídios para análise do seu comportamento frente a fatores ecológico (Luchesi, 1984), e de sua ação sobre o ambiente, especialmente de sua interferência sobre outras emergence. Senna obtusifolia showed lower initial growth rates compared to other weed species. Thus, the Senna obtusifolia species can be caracterized as late infestant plants.

Key words: Growth analysis, weed, Senna obtusfolia.

plantas.

Radosevick \& Holt (1984), comentam que quantidade de matéria seca produzida por uma pl anta in di vidual pode se r propor cional à quantidade de recursos mobilizados durante todo o ciclo, a taxa de crescimento relativo (TCR), que pode ser utilizada como indicador do potencial competitivo de uma espécie. Diversos autores têm utilizado estes parâmetros de crescimento para a análise de experimentos de autoecologia e estudos comparativos entre espécies daninhas e culturas (Patterson \& Flint, 1983; Hocking, 1983; Flint et al., 1984; McWhorter \& Sciumbato, 1988). Grime (1982), verificou após comparar um grande número de plantas daninhas, que a magnitude da TCR pode refletir o tipo de ambiente de origem das mesmas.

Nesta linha de pensamento, o presente trabalho foi instalado visando estudar o crescimento de Senna obtusifolia, espécie muito frequente em áreas de cerrado, e solos cultivados principalmente com a cultura da soja, visando contribuir além do conhecimento da auto-ecologia desta espécie, no auxilio em sistemas de manejo integrado.

\section{MATERIAL E MÉTODOS.}

O presente trabalho foi instalado e conduzido em condições de casa-de-vegetação pertencente ao Departamento de Biologia Aplicada à Agropecuária, da Faculdade de Ciências Agrárias e Veterinárias da UNESP, Campus de Jaboticabal. A semeadura foi realizada em 31/11/1994, depositando-se 20 sementes de Senna obtusifolia 
em vasos plásticos com capacidade para 6 litros, utilizando-se como substrato areia de rio, lavada e peneirada. Para quebrar a dormência ocorrente em sementes desta espécie, as mesmas foram tratadas por 15 minutos com ácido sulfúrico concentrado e, em seguida, lavadas, por igual tempo, em água corrente. Após as plântulas atingirem dois pares de folhas verdadeiras totalmente expandidas, foi realizado o desbaste deixando três plântulas por vaso.

A irrigação foi efetuada com solução nutritiva completa de Hoagland \& Arnon (1950) a $25 \%$ da concentração original durante os primeiros 21 dias e, após este período, até o final do ciclo, a $50 \%$. Para isto, os vasos foram irrigados com volume de solução suficiente até começarem percolar para os vidros coletores previamente conectados ao fundo dos vasos at ra vés de mangueiras.

O experimento foi instalado num deline ame nto experimental inteiramente casualizado com 10 tratamentos (épocas de coleta das plantas) e quatro repetições. As épocas corresponderam a 21, 35, 49, 63, 77, 91, 105, 119, 133, 147 e 161 dias após a emergência (D.A.E.). Em cada coleta, as plantas foram separadas em raízes, caules, folhas, flores e frutos; logo a seguir. foram lavadas por imersão e postas a secar separadamente em estufa de circulação forçada de ar $\left(60-70^{\circ} \mathrm{C}\right)$ por 96 horas e pesadas. Antes da secagem das folhas, foi determinada a área foliar por planta através de um medidor de área foliar.

Com base na área foliar e no peso da matéria seca das diferentes partes da planta, nas respectivas épocas de amostragem, calculou-se: a área foliar específica (AFE), a taxa de crescimentc relativo da área foliar, a taxa de assimilação líquida (TAL), a taxa de crescimento absoluto (TCA) e a taxa de crescimento relativo (TCR), segundc Benincasa (1988).
Os dados primários (matéria seca e área foliar) foram transformados em log. $\operatorname{arcsen} \mathrm{x}$, conforme Hunt (1980), de maneira a satisfazer as hipóteses necessárias para o ajuste de regressão pol inomiais. Os valores de de ter mi na dos parâmetros, citados no item resultados e discussão, correspondem aos dados não transformados.

\section{RESULTADOS E DISCUSSÃO}

Na Figura 1 estão representadas as curvas de regressão polinomial relativas à variação do acúmulo de matéria seca dos componentes da planta de Senna obtusijolia ao longo do ciclo de crescimento.

Todos os componentes da planta, com exceção dos frutos, evidenciaram um padrão comum de resposta, ajustando-se à curva de modelo cúbico, caracterizadas por um forte componente linear compreendido entre os primeiros 119 dias, indicando assim um aumento considerável no peso seco em cada órgão da planta. O máxi mo de acúmulo de matéria seca alcançado pelas plantas foi aos 133 D.A.E., após do qual tendeu a cair, indicando que neste ponto estas já completaram seu ciclo. Os maiores acúmulos de matéria seca foram verificados nos caules e folhas. $\mathrm{O}$ peso seco dos frutos aumentou de forma constante até o final do ciclo onde tendeu a estabilizar-se, ajustando-se a uma cu rva tipo quadrática. O acúmulo total de matéria seca no ciclo de crescimento assemelhou-se àquele descrito para raízes, caules, folhas e flores, uma vez que, o mesmo é uma expressão resultante do somatório destes com os frutos. Os maiores incrementos, entre as avaliações na matéria seca total, foram constatados no período compreendido entre 21 e 91 D.A.E (em média, 200\%) após o qual tendeu a decrescer significativamente. 

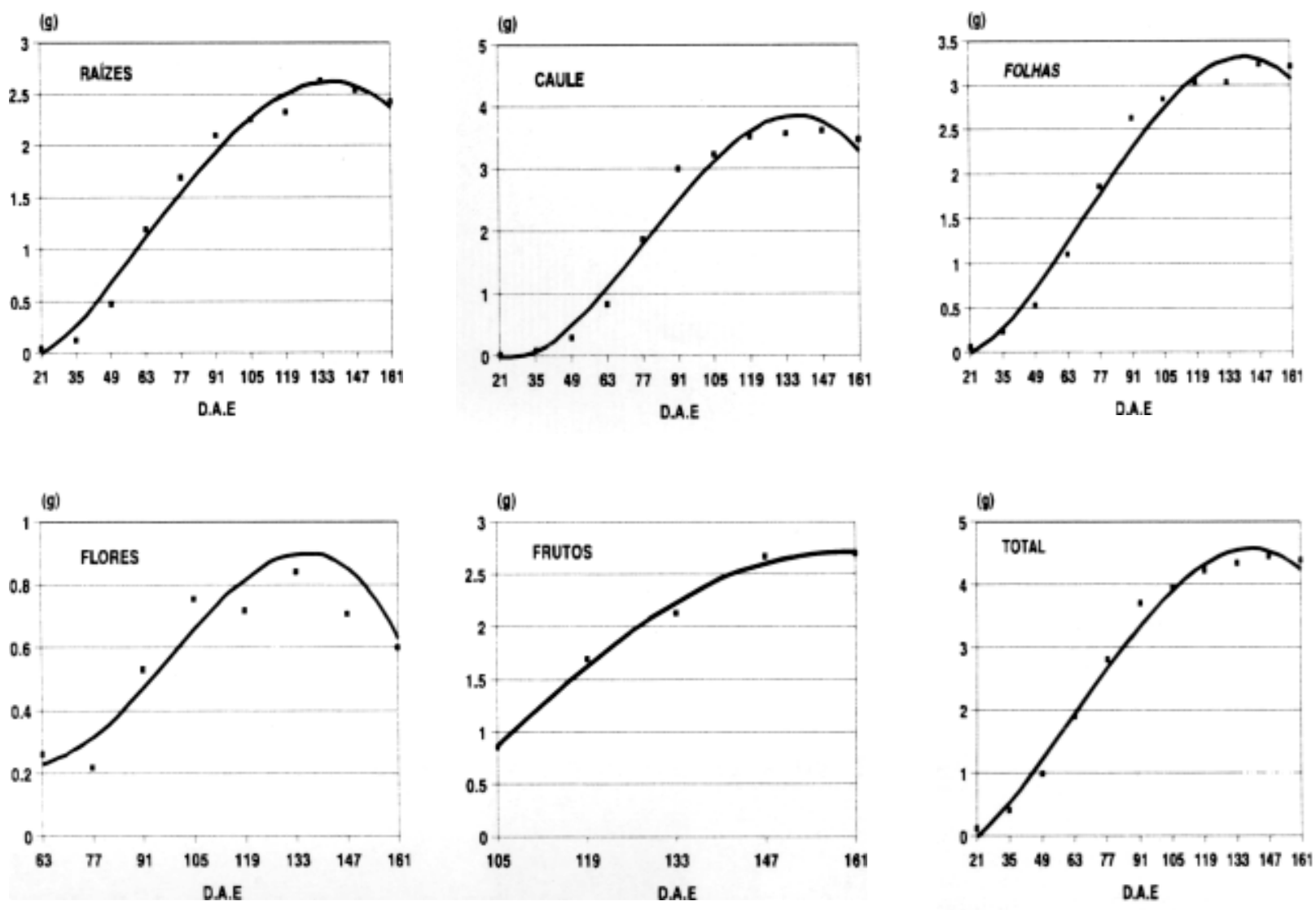

TRANSFOR. - REG. $\log$

FIGURA 01. Acúmulo de Matéria Seca nas diferentes partes da planta de S. obtusifolia ao longo do seu ciclo de crescimento.

A distribuição percentual do peso seco das diferentes partes da planta ao longo do seu ciclo (Figura 2), evidência que. nos primeiros 63 dias de crescimento, a maior concentração de matéria seca estava localizada nas raízes e fol has $(40,76$ e $35,40 \%$, respectivamente), enquanto o caule participou com $24,43 \%$ do total. A partir deste período, ocorreu uma inversão, onde folhas e raízes di minuíram a quantidade de matér ia seca acumulada, aumentando nos caules, sendo que aos 119 D.A.E. a participação destes foram de 13,81; 29.28 e 48,64\%, respectivamente. Já as flores mantiveram uma contribuição de $1,33 \%$ do peso seco total e a dos frutos cresceu até o final do ciclo onde foi de $17,34 \%$. 


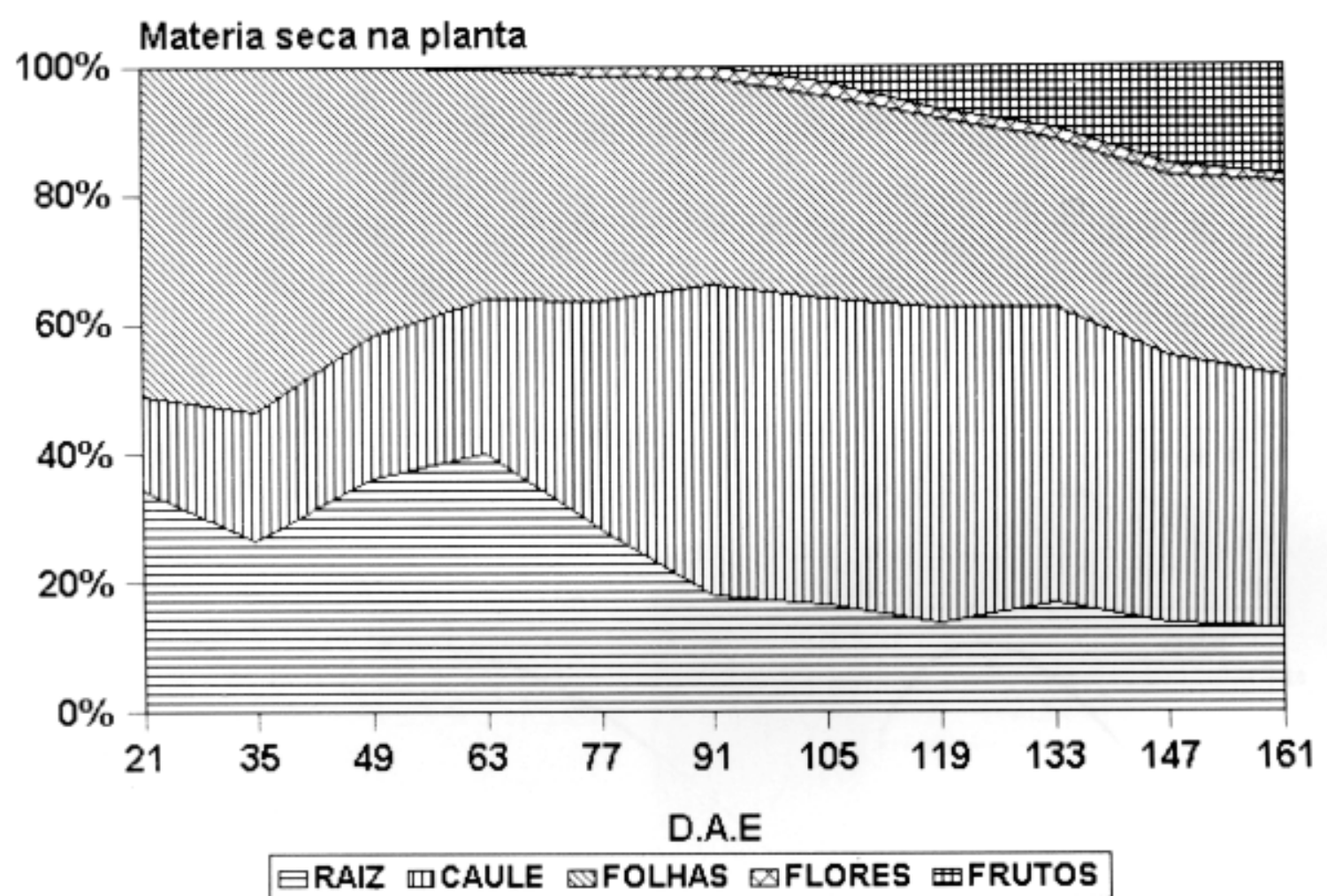

FIGURA 2. Distribui ções percentuais da matéria seca nas diferentes partes da planta de $S$. obtusifolia ao longo do seu ciclo de crescimento.

Ao se analisar as curvas de regressão polinomial relativas à variação das taxas de crescimento absoluto (TCA) de cada componente da planta de S. obtusifolia ao longo do ciclo de crescimento (Figura 3), observa-se claramente que, à semelhança da matéria seca, as raízes, caules e folhas apresentaram um comportamento similar, ajustando-se às curvas de modelo cúbico, onde se evidencia um período de intenso crescimento (35 a 77 D.A.E.) com posterior queda, acentuada até o final do ciclo. As flores apresentaram taxas de crescimento absoluto inicial elevadas (a partir de 49
D.A.E. até 105 D.A.E.) após o qual tiveram valores negativos, período coincidente com a produção de frutos. Nos frutos a TCA diminuiu desde seu início (105 D.A.E.) até o final do ciclo, com leve aumento aos 140 D.A.E. O TCA total expressa o comportamento dos seus componentes principalmente aqueles de maior participação (raízes, caules e folhas), sendo que nos primeiros 91 dias estes componentes cresceram em média 0,$102 ; 0,231$ e $0,183 \mathrm{~g} / \mathrm{dia}$, respectivamente. As plantas cresceram, numa média geral, 0,57 g/d ia. 


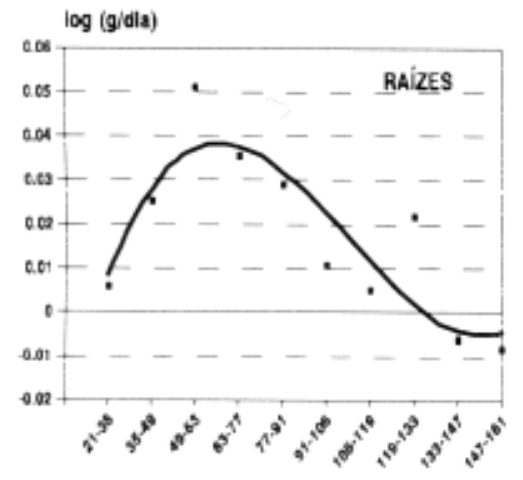

D.A.E

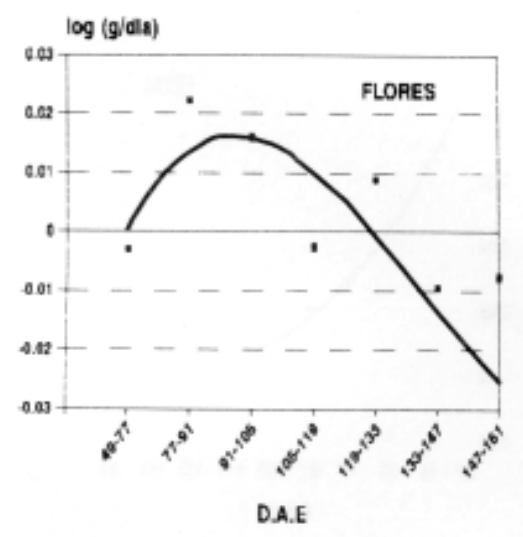

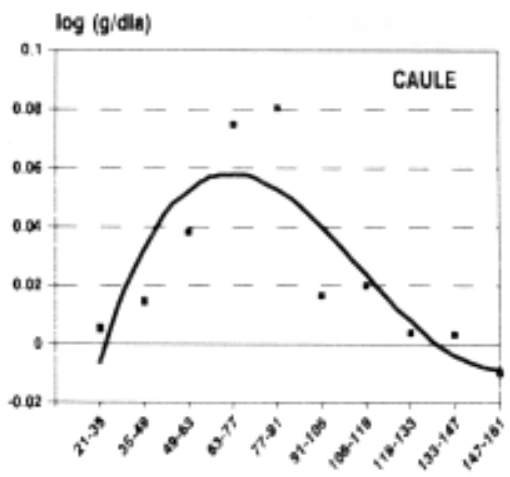

D.A.E

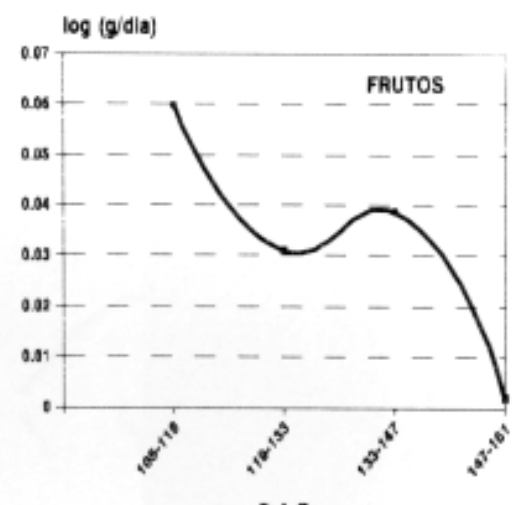

D.A.E

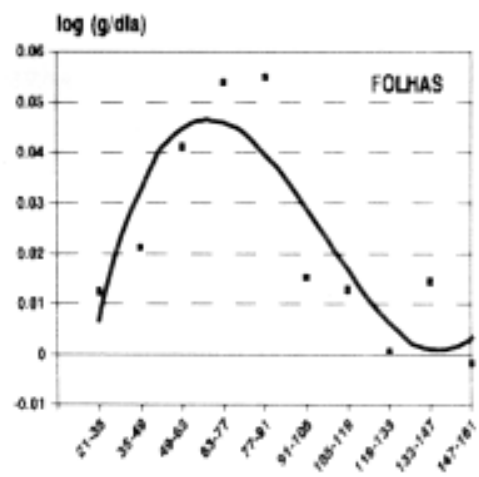

D.A.E

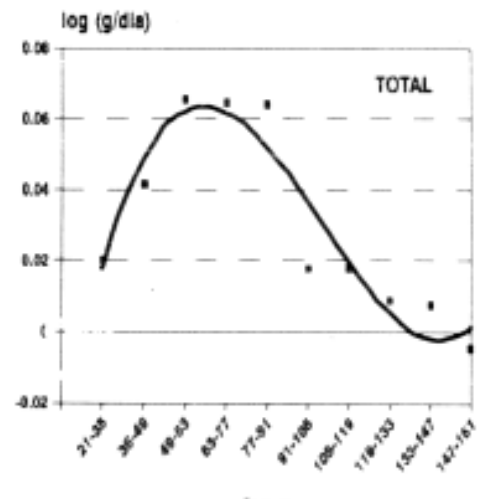

DA.E

TRANSFOR. - REG. log

FIGURA 3. Tax as de crescimento absoluto nas diferentes partes da planta de S. obtusifolia ao longo do seu ciclo de crescimento.

$\mathrm{Na}$ Figura 4, estão representadas as curvas de regressão polinomial relativas à variação das taxas de crescimento relativo (TCR) de cada componente da planta de S. obtusifolia ao longo do seu ciclo de crescimento.

As taxas de crescimento relativo de raízes, caules e folhas evidenciaram uma queda linear progressiva até os 119 D.A.E., a partir do qual tendem a estabilizar-se. A TCR das flores teve um período inicial crescente até 45 D.A.E., após qual decaiu. No entanto, os dados originais demonstram flutuações. A TCR dos frutos decresce rapidamente a partir dos 119 D.A.E. até o final do ciclo. O período de 35 a 91 D.A.E. foi aquele em que os órgãos vegetativos expressaram seus maiores incrementos (TCR maior), destacando-se os caule e folhas. O comportamento da TCR total foi semelhante àquele observado para raiz, caule e folhas, verificando-se uma TCR média para o período citado anteriormente de 0,082 g/g.dia. 

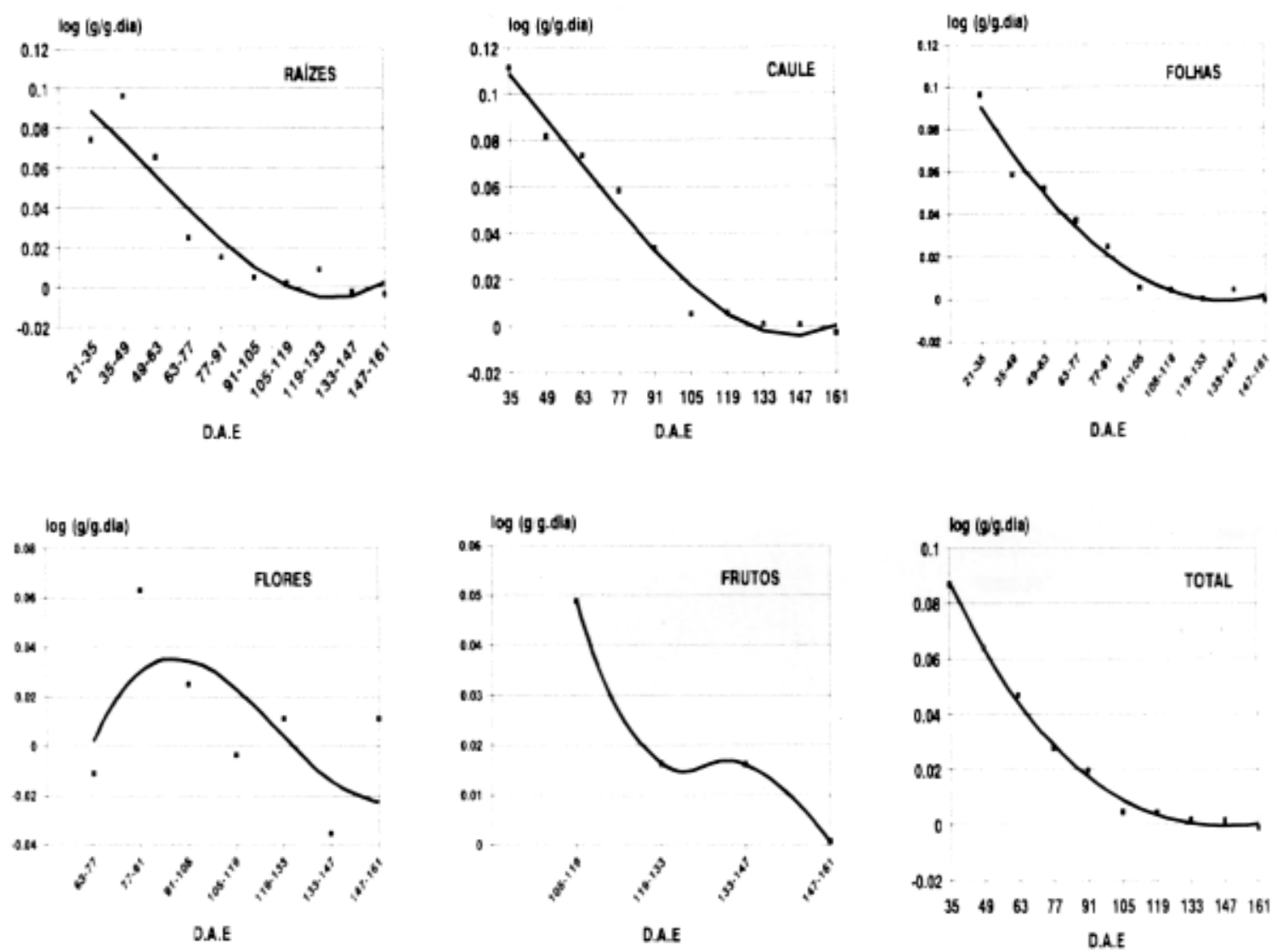

TRANSFOR. - REG. log

FIGURA 4. Taxas de cresciment o relativo nas diferentes partes da planta de S. ohtusifolia o longo do seu ciclo de crescimento.

As curvas de regressão polinomial relativas à variação da área foliar (AF ), taxa de crescimento relativo da área foliar, razão de área foliar (RAF) e taxa de assimilação líquida da planta de $S$. ohtusifolia ao longo do ciclo de crescimento, encontra-se expressas na Figura 5.

A análise destas curvas demonstram que o crescimento da área foliar ajustou-se a um modelo tipo cúbico, com incremento constante pouco acentuado até os 119 U.A.E., após o qual estabilizou-se. Os maiores incrementos nestes parâmetros ocorreram no intervalo de 21 a 35 D.A.E. e dos 49 a 63 D.A.E. constatando-se elevação na área foliar na ordem de 5,4 e 2,0 vezes. respectivamente. A taxa de crescimento relativo da área foliar apresentou uma queda acentuada nos primeiros 91 dias, estabilizando-se a partir dos 105 D.A.E. A RAF decresceu até 105 D.A.E. mantendo-se constante após este período até o final do ciclo. A TAL, por sua vez, mostrou-se idêntica à TCR da área foliar.

Segundo o padrão de alocação de matéria seca total (Figura 1), observado nas plantas de $S$. obtusifolia, podemos afirmar que estas completaram seu ciclo de crescimento aos 133 dias onde alcançaram o máximo de acúmulo de matéria 
seca, entrando logo após em decadência, evidenciando um período vegetativo de 49 dias, a partir do qual surgiram as primeiras flores. Estes valores foram um pouco superiores aos constatados por Tabatini (1993) que, no mesmo local de desenvolvimento deste trabalho, verificou que as
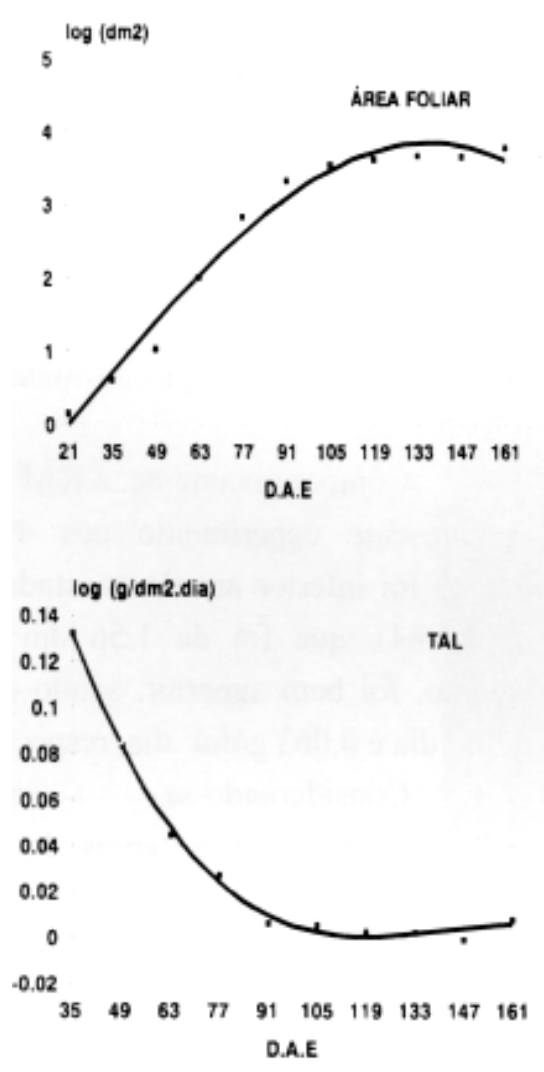

TRANSFOR. - REG. $\log$

FIGURA 05. Áre a foliar, tax a de cre scimento rel ati vo da áre a foliar, tax a de assimi lação líquida e razão da área foliar ao longo do ciclo de crescimento de S. obtusifolia.

Os maiores incrementos de matéria seca ocorreram no o período de 63 a 91 dias, não muito distante daquele verificado por McWhorter \& Sciumbato (1988), entre 72 e 96 dias. Dentro deste período e até o final do ciclo, o caule foi a parte da planta que teve maior participação neste parâmetro,

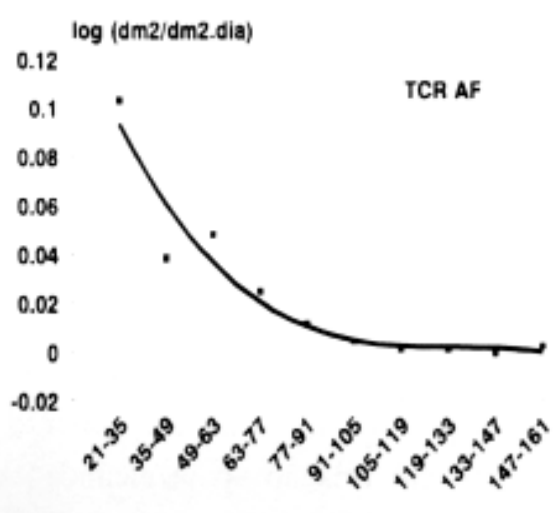

plantas de $S$. ohtusifolia apresentaram um ciclo de 130 dias com um período vegetativo de 56 dias. Retzinger (1984), estudando plantas de $S$. obtusifolia provenientes de fontes diferentes dos E.U.A., constatou que o período vegetativo variou de 52 até 80 D.A.E.

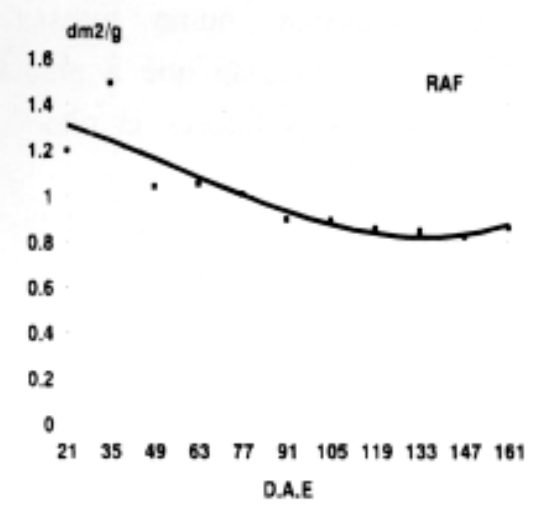


vagens ocorreram nesses ramos. Uma vez que no período citado anteriormente constatou-se que a TCR para o caule apresentou valores bem baixos e uma redução da participação porcentual de raízes e folhas no acúmulo de matéria seca total, pode-se supor ocorrência de redistribuição de material orgânico destes últimos para caules e frutos.

Baseados na citação de Benincasa (1988) a qual explica que a TCA fornece uma idéia da velocidade de crescimento das plantas, pode-se afirmar que $S$. obtusifolia cresceu mais rapidamente nos primeiros 63 dias, apresentando uma taxa média de $0,134 \mathrm{~g} /$ dia. Esta afirmação se complementa com o comportamento da TCR neste mesmo período, onde se constataram os maiores valores $\mathrm{e}$ decréscimos. Tal comportamento se justifica, uma vez que, no início do crescimento o incremento de peso em relação ao já alcançado é maior devido ao menor dispêndio na manutenção $\mathrm{e}$ autosombreamento, expresso numa fotossíntese líquida mais elevada. À medida que a planta se desenvolve aumentam estes fatores já citados e, conseqüentemente, a TCR cai.

As plantas de $S$. obtusifolia aos 63 D.A.E. apresentaram uma TCR média de 0,091 g/g.dia, valor este superior ao constatado por Adcok \& Banks (1991) que, estudando comparativamente as TCR de S. obtusifolia e da cultura da soja (35 D.A.E.) em condições de casa de vegetação, observaram valores de $0,08 \mathrm{~g} / \mathrm{g}$ dia e $0,06 \mathrm{~g} / \mathrm{g}$ dia, respectivamente.

O aumento em peso de matéria seca e, consequentemente, das TCR, deverão estar diretamente ligados à captação e conversão de energia solar pela planta. Sendo as folhas os órgãos responsáveis por estes fenômenos, o estudo dos parâmetros relacionados com elas justificaram as respostas citadas anteriormente. Observa-se que o período de maior crescimento da área foliar (Figura 5) concentrou-se naquele citado para a TCR (63 dias), bem como a área útil fotossintética (RAF) e a TAL, as quais diminuíram após este período corno uma consequiência do auto-sombreamento da planta. Flint et al. (1984) e Sims \& Oliver (1990) relatam que as plantas de $S$. obtusifolia ao redor dos 56 D.A.E. tendem a bloquear a passagem da luz para as folhas inferiores provocando senescência, devido que, nesta idade, as plantas fecham totalmente o dossel. A redução mais acentuada da TAL comparada a RAF. nos primeiros 63 dias, nos leva a hipótese de que a queda da TCR neste período foi consequiência maior da diminuição da quantidade de matéria seca, produzida pela planta por unidade foliar (TAL), do que da área foliar útil, para produção desta matéria seca (RAF). Isto indica que, até esta fase, a planta já desenvolveu praticamente toda a sua capacidade de crescimento, investindo, a partir de agora, na manutenção e também na redistribuição de material para a parte reprodutiva. Comparativamente, a RAF foliar verificada no presente experimento aos 49 D.A.E. $\left(1,07 \mathrm{dm}^{2} / \mathrm{g}\right)$ foi inferior àquela constada por FLINT et al. (1984), que foi de $1,56 \mathrm{dm}^{2} / \mathrm{g}$. A TAL, no entanto, foi bem superior, sendo os valores $0,236 \mathrm{~g} / \mathrm{dm}^{2}$.dia e $0,063 \mathrm{~g} / \mathrm{dm}^{2}$.dia, respectivamente.

Considerando-se um período correspondente a dois terços do ciclo médio de culturas anuais, de dez semanas, S. obtusifolia quando comparada a outras espécies daninhas, apresenta taxas de crescimento inicial menores, o que pode caracterizá-la corno urna planta infestante tardia.

\section{LITERATURA CITADA.}

ADCOCK, T.E., BANKS, A.P. Effects of chlorimuron on soybean (Glvcine max) and sicklepod (Serena obtusilfolia) as influenced by ap pl ic ations timing. We ed Sci., v.39, p.139-142, 1991

BENINCASA, M.M.P. Análise de crescimento de pl an ta s; no çõ es bá si ca s. Jab ot ic abal: FUNEP, 1988. 42p.

Planta Daninha, v. 15, n. 2, 1997. 
FLINT, E.P., PATTERSON, D.T., MORTENSEN, D.A., RIECHERS, G.H., BEYERS, J.L. Temperature effects on growth and leaf production in three weed species. Weed Sci., v.32.115, p. 655-653, 1984.

GRIME, J.P. Estrategias de adaptacion de las plantas y procesos que controlan la vegetacion. Mexico: Limusa, 1982. p.61.

GUSTAVSSON, A.D. Growth of annual dic otyled ono us weeds. Uppsala: SLU, 1989. $108 \mathrm{p}$.

HOAGLAND, D.R., ARNON, D.J. The water culture method of growing plants without soil. Berkeley: University of California, 1950 .

HOCKING. P.S. Feature of the growth and mineral nutrition of noozooraburr (Xanthium occidentale Bertol.) a noxious weed in Central New South Wales. Austr. J. Agris. Res., v.34. n2, p.155-66. 1983.

HUNT. R. Plant growth curves. Londres: Edward Arnold, 1982. p.75.

LUCCHESI. A.A. Utilização prática da análise de crescimento ve ge ta l. An. Esc. Super. Agric. Luiz de Queiroz- Univ. São Paulo, Piracicaba, v.41, p.181-202, 1984.

McWHOR TER, G.S., SCIUMB ATO, G.L. Effect of row spacing, be nomyl, and duration of sicklepod (Selina ohtusifoliu) interference on soybean (Glycine max) yields. Weed Sci., v.36, n.2., p.254-9, 1988.

PAT TERSON, D.T., FLIN T, E.P. Comparative water relations, photosyntehes is and growth of soybean (Glycine max) and seven associated weeds. Weed Sci., v. 31, n. 3, p.318-23, 1983.

RADOSEVICH, S.R., HOLT, J.S. Weed ecology: implication for vegetation management. New York: John Wiley \& Sons, 1984. p.181-82.

RETZINGER JR., E. Growth and development of sicklepod (Senna ohtusifolia) selections. Weed Sci., v.32, n.5, p.608-611, 1984.

ROUSH, M.L., RADOSEVICH, S.R., MAXWELL. B.D. Future outlook for herbicide-resistance research. Weed Technol., v.4, n.1, p.208-214, 1990.

SIMS, B.D., OLIVER, L.R. Mutual influences of seedling johnsongrass (Sorghum halepense), sicklepod (Senna obtusifolia), and soybean (Glycine max). Weed Sci., v.3, p.138-147, 1990.

TAB AT IN I, S. M. Fenologia e alocação de recursos em Senna obtusifolia L. em função da época de plantio. Jaboticabal. Trabal ho apresentado à Faculdade de Ciências Agrárias e Veterinárias - UNESP, para graduação em Agronomia, 1993. 37p. 